\title{
PEMANFAATAN SUMBER DAYA LOKAL UNTUK MENINGKATKAN UMKM DUSUN PULO GULUREJO
}

\author{
Setia Wardani ${ }^{1}$ Rianto $^{2}$, Anis Febri Nilansari ${ }^{3}$ \\ Informatika, Sains dan Teknologi \\ Universitas PGRI Yogyakarta \\ Jl. PGRI I No 117 Sonosewu Kasihan Bantul \\ Email: ${ }^{1}$ setia@upy.ac.id, ${ }^{2}$ rian_r@ymail.com, ${ }^{3}$ anis@upy.ac.id
}

Received: Maret 2020; Accepted : April 2020; Published : Juli 2020

\begin{abstract}
Abstrak
Mitra pada Pengabdian kepada Masyarakat (PkM) ini adalah Kelompok Wanita Tani (KWT) yang bergerak pada bidang pertanian, berlokasi di Dusun Pulo Kalurahan Gulurejo Kapanewon Lendah Kabupaten Kulon Progo berjarak 28,7 km dari Universitas PGRI Yogyakarta (UPY). Masalah utama pada mitra adalah melimpahnya hasil pertanian dari KWT berupa pisang yang belum dikelola dan dimanfaatkan oleh masyarakat untuk menambah pendapatan keluarga karena belum adanya pengarahan tentang pengolahan makanan ringan, jangkauan pasar yang masih lokal dan desain produk yang masih konvensional. Tujuan PkM adalah membentuk dan mengembangkan kelompok usaha di Dusun Pulo yang mandiri secara ekonomi dengan memberikan solusi atas masalah pada mitra. Solusi untuk mengatasi masalah pada mitra antara lain dengan metode penyuluhan dan pelatihan diantaranya (1) Penyuluhan dan Pelatihan pengolahan pisang, (2) Pelatihan pengemasan produk, (3) Pelatihan manajemen pemasaran produk dengan memanfaatkan Teknologi Informasi dan Komunikasi (TIK). Hasil dari PkM ini adalah kripik pisang yang telah dikemas, promosi produk dengan memanfaatkan TIK serta artikel yang dipublikasikan pada jurnal pengabdian masyarakat.
\end{abstract}

Kata Kunci: Kelompok Wanita Tani, Dusun Pulo Gulurejo, pisang, TIK, pemasaran

\begin{abstract}
The partner on community Service (PkM) is a women farmer group (KWT) engaged in agriculture, located in the hamlet of Pulo Kalurahan Gulurejo, the current district of Kulon Progo is $28.7 \mathrm{~km}$ from PGRI Yogyakarta University (UPY). The main problem with the partner is the abundance of agricultural products from KWT in the form of bananas that have not been managed and utilized by the community to increase family income because there is no guidance on the processing of snacks, the market reach Still local and design products are still conventional. The purpose of PkM is to establish and develop business groups in the economically independent village of Pulo by providing solutions to partners problems. Solutions to solve problems with the partners, among others, with the methods of counseling and training (1) banana Treatment and training, (2) Product packaging training, (3) Product marketing management training by utilizing technology Information and communication (ICT). The results
\end{abstract}


of this PkM are banana chips that have been packaged, the promotion of products by utilizing ICT and articles published on the Journal of Community Devotion.

Keywords : Women farmer group, village Pulo Gulurejo, Banana, ICT, marketing

\section{Latar Belakang Masalah}

Perkembangan sektor industri dalam pembangunan di Indonesia tidak terlepas dari peranan dan keberadaan industri kecil [1]. Secara historis, UMKM Indonesia selalu menjadi pemain utama dalam kegiatan ekonomi domestik dengan menyumbang lebih dari 99 persen dari semua perusahaan yang ada di seluruh sektor dan menyediakan lapangan kerja bagi lebih dari 90 persen tenaga kerja negara [2]. Di Uganda, UMKM memainkan peran penting dalam menciptakan peluang kerja yang memungkinkan tercapainya pertumbuhan dan pembangunan yang adil dan berkelanjutan[3]. Usaha Mikro Kecil Menengah (UMKM) umumnya dianggap sebagai penggerak pertumbuhan ekonomi dan pemerataan pembangunan dalam suatu negara berkembang[4], dimana UMKM mempunyai peranan dalam mengurangi mengurangi pengangguran dan kemiskinan khususnya untuk negara-negara berkembang[5] serta persaingan regional, nasional, maupun internasional perlu ditingkatkan kualitas dan kapasitas produksi[6] dan dibutuhkan komitmen, kemauan yang kuat dalam meningkatkan produktifitas UMKM. Akan tetapi banyak UMKM di seluruh dunia memiliki sedikit pengetahuan tentang manajemen lingkungan dan tidak mengerti konsep manajemen lingkungan[7]. Sehingga, sangat sulit bagi UMKM untuk melihat hubungan yang jelas antara implementasi sistem manajemen lingkungan dan manfaat yang ditawarkannya[8].

Penelitian pengembangan UMKM di Indonesia, yang berfokus pada kelompok UMKM di industri manufaktur mengklasifikasikan klaster manufaktur UMKM di Indonesia menjadi empat jenis yaitu artisinal, cctive, dynamic dan advanced[9] dimana klaster artisinal mendominasi klaster di Indonesia[10]. Sifat operasi, kinerja, struktur aset, kewajiban, modal, peluang pendanaan, perekrutan karyawan, pelatihan, kualifikasi mereka dan banyak elemen lain yang pada dasarnya berbeda dari yang dimiliki perusahaan besar[11], akan tetapi jaringan adalah cara yang berguna bagi pemilik UMKM untuk memperluas keahlian pemasaran dan meningkatkan kinerja[12]. Jaringan bisnis mengacu pada asosiasi bisnis gratis, yang mampu menciptakan struktur dan proses, pengambilan keputusan bersama dan mengintegrasikan upaya anggota untuk merancang dan memproduksi barang dan jasa, dan bertukar informasi dan sumber daya lainnya[13]. Jaringan dalam UKM mengacu pada proses jaringan yang dilakukan oleh pemilik UMKM dalam mengelola kegiatan bisnis[14]. Sehingga penggunaan teknologi informasi menjadi penting pemasaran produknya[15].

Dusun Pulo merupakan salah satu dari sepuluh dusun yang berada pada Kalurahan Gulurejo dan dikepalai oleh seorang Dukuh, Dusun Pulo berjarak sekitar 28,7 Km dari Universitas PGRI Yogyakarta, $12 \mathrm{~km}$ dari Kapanewon Lendah dan $25 \mathrm{~km}$ dari Kabupaten Kulon Progo. Dusun Pulo berbatasan dengan beberapa wilayah yaitu sebelah utara berbatasan dengan Dusun Mendiro, sebelah selatan berbatasan dengan Sungai Progo, sebelah timur berbatasan dengan Kabupaten Bantul, dan sebelah barat berbatasan dengan Dusun Pengkol. Luas wilayah Pedukuhan Pulo yaitu $658.627 \mathrm{~m}^{2}$ dengan luas tanah warga $276.827 \mathrm{~m}^{2}$, makam $1.800 \mathrm{~m}^{2}$, jalan $2000 \mathrm{~m}^{2}$, wedi kengser $300.000 \mathrm{~m}^{2}$, Tanah Sultan Ground (SG) Komplek Pengkol $60.000 \mathrm{~m}^{2}$. Jumlah penduduk di Dusun Pulo sebanyak 836 jiwa, terdiri dari 416 laki-laki dan 420 
perempuan, rata-rata penduduk laki-laki bermata pencaharian sebagai petani dan buruh pasir di Sungai Progo, sedangkan untuk perempuan sebagai ibu rumah tangga.

Pada Tahun 2017 Kepala Dusun Pulo membentuk Kelompok Wanita Tani (KWT) yang bergerak pada bidang pertanian untuk mengelola usaha pertanian masyarakat diantaranya pisang jenis raja bandung/raja uter. Pisang (Musa paradisiaca) merupakan buah yang mengandung sumber karbohidrat, mineral serta vitamin B6 dan vitamin $\mathrm{C}$ yang tinggi [16]. Kandungan karbohidrat sederhana dan kompleks yang ada pada pisang dapat bermanfaat sebagai sumber energi bagi tubuh. Pembentukan KWT dilakukan dengan tujuan meningkatkan pendapatan masyarakat di dusun melalui bidang pertanian, berbagai pelatihan mulai dari cara tanam, perawatan dan pemberian pupuk pada kedua tanaman dilakukan pendampingan dari Dinas Pertanian Kabupaten Kulon Progo, namun sering berjalannya waktu KWT Dusun Pulo mendapatkan berbagai masalah diantaranya adalah melimpahnya hasil panen masyarakat dikarenakan nilai jual yang tidak sebanding dengan waktu dan biaya perawatan bibit tanaman sampai dengan menghasilkan buah untuk dijual, serta animo masyarakat lokal untuk mengkonsumsi hasil pertanian pada KWT Dusun Pulo sangat rendah, hal ini mengakibatkan hasil pertanian tersebut dijadikan makanan ternak.

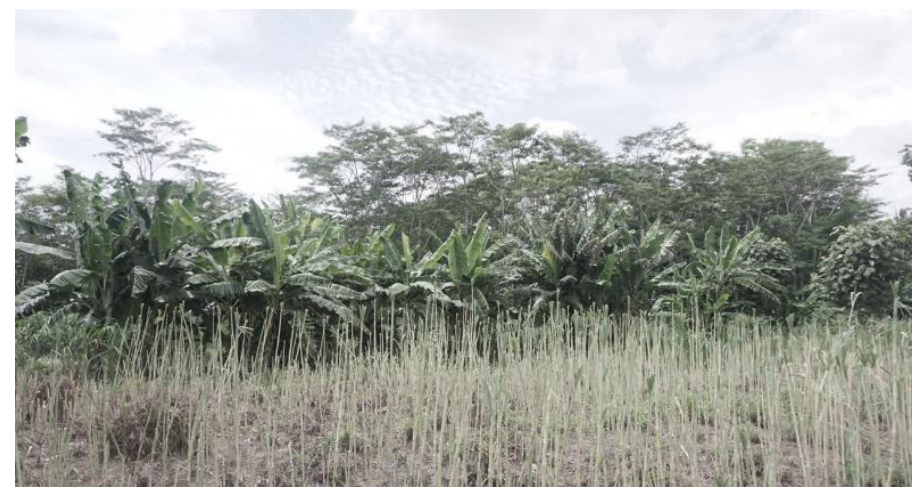

Gambar 1. Tanaman Pisang Dusun Pulo

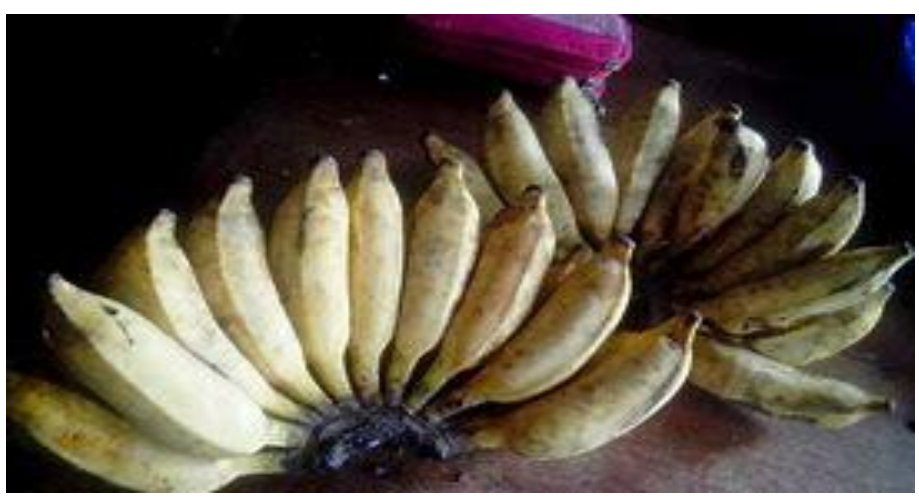

Gambar 2. Pisang Raja Bandung/Raja Uter 


\section{Masalah}

Berdasarkan observasi dari tim pengabdi Universitas PGRI Yogyakarta (UPY), pokok permasalahannya adalah anggota KWT belum memanfaatkan potensi alam yang ada (hasil pertanian) dijadikan produk makanan ringan. Untuk mengatasi masalah yang ada, tim pengabdi mengajak anggota KWT untuk memanfaatkan hasil pertanian mereka berupa pisang agar dapat dimanfaatkan sebagai makanan ringan, pelatihan pengemasan produk dan pemasaran dengan memanfaatkan Teknologi Informasi dan Komunikasi (TIK). Tujuan Pengabdian ini antara lain (1) meningkatkan kreativitas anggota KWT dalam pengolahan hasil pertanian berupa pisang menjadi makanan ringan, (2) meningkatkan kesadaran masyarakat tentang pengelolaan sumber daya pangan lokal yang mampu meningkatkan pendapatan masyarakat, (3) menjadi oleh-oleh khas Dusun Pulo bahkan Kalurahan Gulurejo yang sedang merintis desa wisata.

\section{Metode}

Untuk menyelesaikan masalah yang ada pada KWT Dusun Pulo, solusi yang dilakukan oleh tim pengabdi antara lain metode penyuluhan yaitu berupa penyuluhan tentang diversifikasi produk makan olahan yang berasal dari pisang, metode pelatihan yaitu pelatihan pengolahan makanan menjadi makanan ringan, pelatihan pembuatan desain produk, pelatihan pengemasan produk menggunakan plastik dan pelatihan pembuatan akun facebook dan instagram untuk promosi produk, sedangkan untuk metode pendampingan dilaksankan berupa pendampingan produksi dan pemasaran. Berikut adalah tabel 1 pelaksanan kegiatan PKM pada KWT Dusun Pulo.

Tabel 1. Kegiatan yang dilakukan

\begin{tabular}{|c|c|c|}
\hline No & Kegiatan & Langkah-langkah \\
\hline \multicolumn{3}{|c|}{ Persiapan } \\
\hline 1 & $\begin{array}{l}\text { Perijinan ke Kalurahan Gulurejo dan } \\
\text { Padukuhan Pulo }\end{array}$ & $\begin{array}{l}\text { a. Pembuatan permohonan surat ijin } \\
\text { ke LPPM untuk kegiatan }\end{array}$ \\
\hline & & $\begin{array}{l}\text { Pengabdian kepada Masyarakat. } \\
\text { b. Perijinan pada Kalurahan } \\
\text { Gulurejo }\end{array}$ \\
\hline & & c. Perijinan pada Padukuhan Pulo \\
\hline 2 & $\begin{array}{l}\text { Koordinasi mitra terkait kegiatan } \\
\text { Pengabdian kepada Masyarakat }\end{array}$ & $\begin{array}{l}\text { a. Menentuan lokasi kegiatan PkM } \\
\text { b. Menentukan waktu dan tanggal } \\
\text { pelaksanaan PkM }\end{array}$ \\
\hline \multicolumn{3}{|c|}{ Pelaksanaan } \\
\hline 1 & $\begin{array}{l}\text { Penyuluhan dan Pelatihan pengolahan } \\
\text { hasil pertanian menjadi makanan ringan }\end{array}$ & $\begin{array}{l}\text { a. Penyuluhan tentang diversifikasi } \\
\text { produk makan olahan yang } \\
\text { berasal dari pisang } \\
\text { b. Pelatihan pengolahan makanan } \\
\text { menjadi makanan ringan }\end{array}$ \\
\hline 2 & Pelatihan pengemasan produk & $\begin{array}{l}\text { a. Pelatihan pembuatan desain } \\
\text { produk } \\
\text { b. Pelatihan pengemasan produk } \\
\text { menggunakan plastik }\end{array}$ \\
\hline
\end{tabular}




\begin{tabular}{l|l|l|} 
Pelatihan dan Pendampingan & a. Pelatihan pembuatan akun \\
manajemen promosi berbasis TIK & $\begin{array}{l}\text { facebook dan Instagram untuk } \\
\text { promosi produk } \\
\text { b. Pendampingan dan evaluasi }\end{array}$ \\
\hline
\end{tabular}

\section{Hasil dan Pembahasan}

Metode pelaksanaan PKM di Dusun Pulo adalah penyuluhan, pelatihan dan pendampingan pengolahan Sumber Daya Alam (SDA) lokal berupa pisang menjadi olahan yang bernilai ekonomis tinggi. Pelatihan disertai dengan manajemen pemasaran produk dengan memanfaatkan TIK. Penerapan penyuluhan diawali dengan menentukan sarana dan prasaranan yang diperlukan dalam melakukan diversifikasi dari produk KWT yaitu berupa pisang, dilanjutkan dengan cara pengolahan dan pengemasan pisang menjadi keripik yang memiliki nilai ekonomis tinggi. Pelatihan pemanfaatan TIK dimaksudkan agar jangkauan pemasaran dapat dilakukan secara luas sehingga produk dapat dikomersialisasikan secara lokal dan konvensional namun juga melalui media sosial. Peserta PkM adalah anggota KWT di Dusun Pulo, yang bertujuan memberikan keterampilan kepada anggota KWT tidak hanya bergerak dalam bidang pertanian, namun juga dalam mengolah hasil pertanian atau SDA lokal menjadi produk keripik pisang. Kegiatan PkM yang telah dilakukan antara lain sebagai berikut :

a. Penyuluhan dan Pelatihan Pengolahan Hasil Pertanian

Sebelum penyuluhan dan pelatihan pengolahan hasil pertanian dimulai, acara diawali dengan sambutan pihak KWT Dusun Pulo. Sambutan yang dilakukan sekaligus membuka acara yang diikuti oleh warga masyarakat Dusun Pulo yang dominan diikuti oleh ibu-ibu. Peserta penyuluhan dan pelatihan yang dilakukan diikuti oleh 40 warga Dusun Pulo. Penyuluhan diawali dengan materi pemilihan bahan dan alat yang diperlukan untuk melakukan diversifikasi produk hasil sumber daya alam yaitu pisang menjadi keripik yang memiliki nilai ekonomis tinggi. Pemilihan bahan dan alat meliputi bahan dalam pembuatan keripik pisang yaitu Pisang Raja Bandung atau Uter yang sudah matang, garam halus, minyak goreng, kapur sirih, penyedap rasa dan air putih. Penyuluhan juga dilakukan dengan menyampaikan materi cara memilih bahan utama yaitu Pisang Raja Bandung atau Uter yang baik dan tepat untuk diolah menghasilkan keripik, namun sebagian besar Pisang Raja Bandung atau Uter dapat diolah menjadi keripik tergantung pada kualitasnya saja. Pisang Raja Bandung atau Uter yang memiliki kualitas tinggi dapat kita pilah dengan Pisang Raja Bandung atau Uter yang memiliki kualitas yang biasa sehingga nantinya penentuan harga akan berbeda juga.

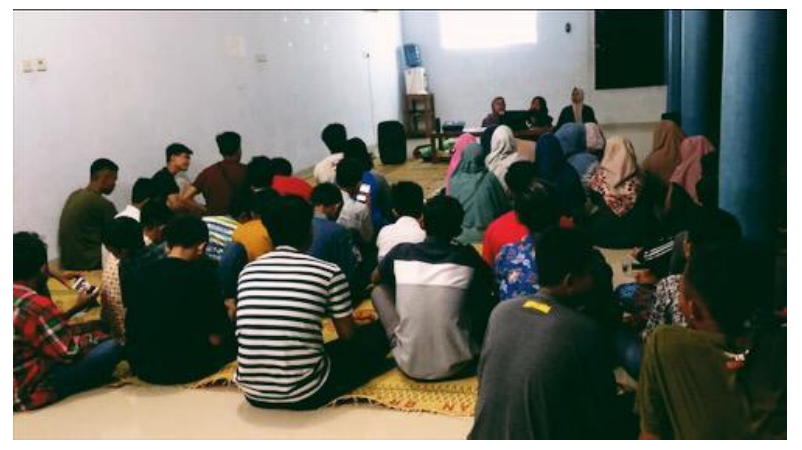

Gambar 3. Penyuluhan dan Pengolahan Hasil Pertanian 
Setelah melakukan tahapan pemilihan bahan baku dan alat yang diperlukan dalam diversifikasi pisang menjadi keripik, dilanjutkan dengan pelatihan pengolahan pisang. Pelatihan pengolahan pisang di awali dengan memberikan materi penyuluhan terkait cara mengolah produk yaitu pisang menjadi keripik yang masih terjaga nilai manfaat dan gizinya. Penyuluhan pengolahan berupa pemilihan minyak dan cara menggoreng yang tepat, pemilihan bumbu tambahan berupa penyedap rasa yang aman dikonsumsi, dan cara menentukan ketebalan keripik pisang. Ketebalan dalam menentukan keripik pisang sangat mempengaruhi hasil akhir produk oleh karena keripik yang tipis dan renyah tidak banyak menyerap minyak sehingga akan lebih menarik dan enak untuk dikonsumsi.

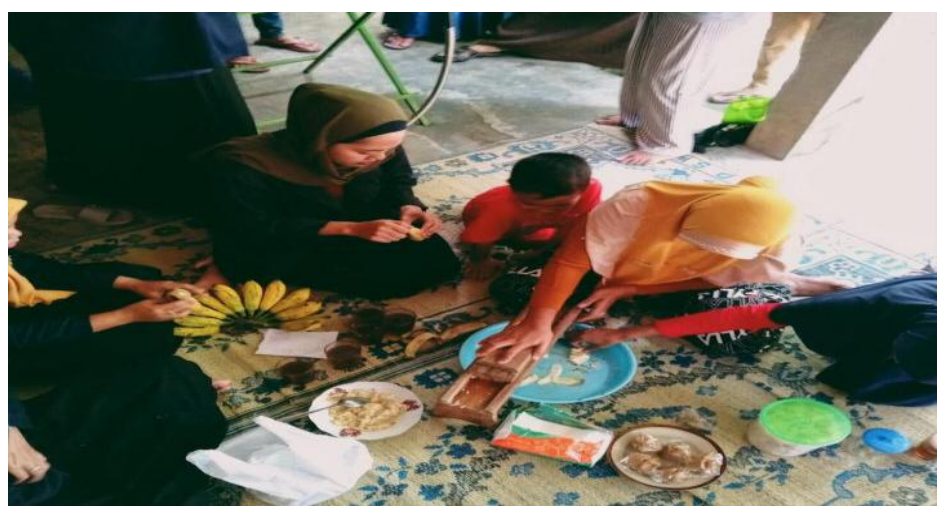

Gambar 4. Cara menentukan ketebalan keripik pisang

Tahapan yang paling penting pada PkM ini yaitu pada tahap pelatihan pengolahan produk. Pemahaman peserta pelatihan yaitu masyarakat Dusun Pulo dalam mengolah hasil pertanian menjadi produk yang bernilai jual tinggi akan menentukan keberlanjutan kegiatan yang dilakukan. Oleh sebab itu masyarakat harus benar-benar memahami setiap proses yang dilakukan. Proses pengolahan pisang menjadi keripik dilakukan oleh pemateri didampingi oleh mahasiswa. Pemateri meberikan arahan berupa cara pengolahan disertai dengan praktek langsung pengolahan pisang menjadi keripik. Antusisme anggota KWT Dusun Pulo dalam kegiatan PkM dapat dilihat pada pada gambar 5.

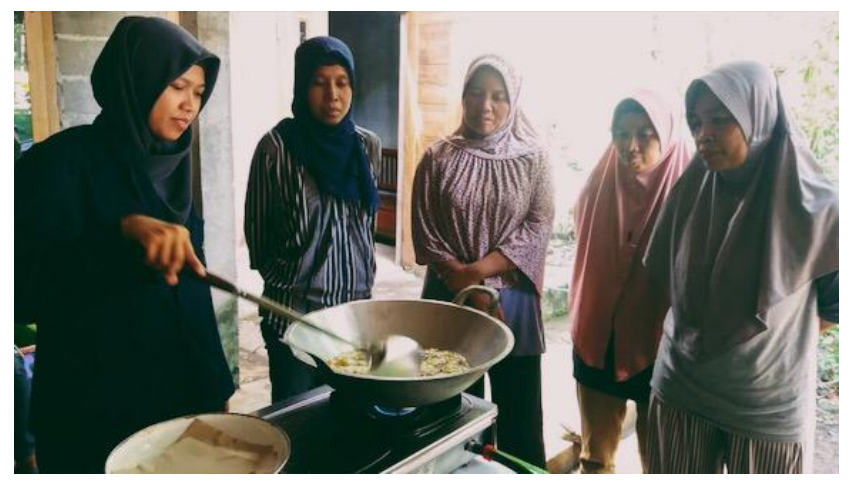

Gambar 5. Arahan cara menggoreng keripik yang tepat 
b. Pelatihan Pengemasan Produk

Pelatihan pengemasan produk dilakukan setelah pengolahan keripik pisang selesai dilakukan. Pemateri perlu menyampaikan mengenai materi pelatihan pengemasan produk oleh karena produk yang menarik akan menjadi nilai jual tersendiri agar dapat diminati konsumen. Penampilan dari produk merupakan langkah awal konsumen dalam menentukan untuk membeli produk tersebut, sehingga selain cara pengolahan keripik pisang, cara pengemasan yang menarik juga menjadi tahap yang penting dalam pengabdian kepada masyarakat berupa pengolahan hasil pertanian menjadi produk yang memiliki nilai ekonomis tinggi. Pelatihan pengemasan produk diawali dengan memberikan penyuluhan terlebih dahulu mengenai cara pemilihan pengemas yang menarik, yang aman untuk mengemas produk makanan dan yang membuat keripik tetap terjaga kualitasnya. Pengemas yang paling cocok untuk produk kripik pisang yaitu berupa plastik wrap. Keripik merupakan produk yang harus terjaga tingkat kerenyahannya, sehingga dengan menggunakan plastik wrap maka keripik yang sudah dibuka dapat ditutup kembali dan terhindar dari udara terbuka sehingga produk tetap terjaga kualitasnya. Produk keripik juga merupakan sediaan yang menyerap minyak oleh karena proses penggorengan, oleh karena itu sebelum produk dikemas harus dapat dipastikan bahwa minyak terlebih dahulu terserap di kertas tisu. Gambar 6. contoh produk keripik pisang yang sudah dikemas menggunakan plastik klip berdiri.

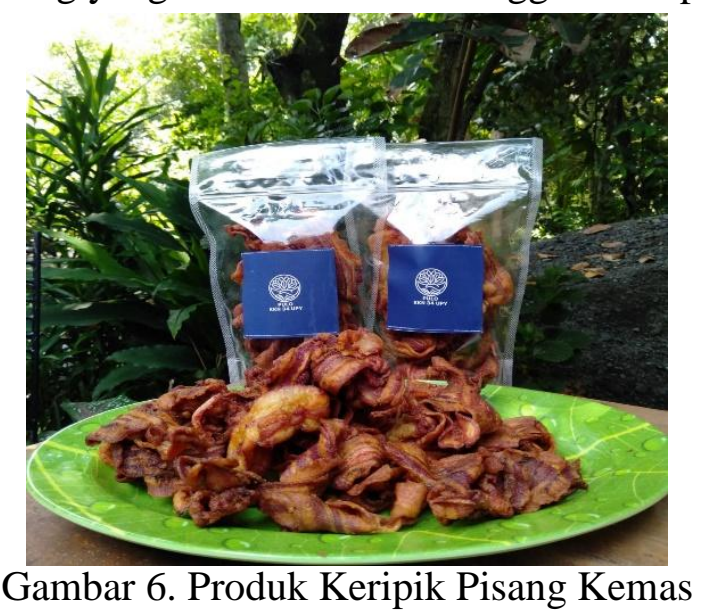

Pelatihan pengemasan produk tidak hanya selesai sampai produk sudah selesai dikemas, namun juga dilanjutkan berupa pemberian label produk kerpik pisang. Pembuatan desain label keripik pisang disesuaikan dengan anggota KWT di Dusun Pulo sehingga dapat menjadi ciri khas dan pembeda dengan produk keripik pisang lainnya. Pembuatan desain dilakukan oleh pemateri didampingi peserta yaitu anggota KWT Dusun Pulo. Desain dibuat berupa gambar dua tangan yang sedang berjabat tangan yang menandakan bahwa produk keripik merupakan hasil olahan bersama anggota KWT di Dusun Pulo. Diatas gambar tangan yang berjabat tangan terdapat gambar daun yang menandakan bahwa bahan baku utama yaitu berupa hasil bumi masyarakat Dusun Pulo berupa Pisang Raja Bandung atau Uter. Penggunaan label pada produk selain dapat digunakan sebagai pembeda produk Dusun Pulo dengan produk serupa lain, dapat juga digunakan sebagai media agar produk yang dikemas dapat menarik. 
c. Pelatihan dan Pendampingan manajemen promosi berbasis TIK

Produk yang sudah dikemas dengan menarik dan siap untuk di komersialisasikan selanjutnya dilakukan tahap pelatihan dan pendampingan promosi berbasis TIK. Pemasaran produk keripik pisang Dusun Pulo dilakukan dengan menggunakan TIK dengan tujuan agar produk dapat dipasarkan secara luas sehingga menambah konsumen dan pendapatan anggota KWT Dusun Pulo. Peserta dalam pelatihan dan pendampingan manajemen promosi berbasis TIK sebagian besar ialah ibu-ibu anggota KWT, sehingga diperlukan pendampingan dari pihak generasi muda di Dusun Pulo untuk mengikuti pelatihan. Gambar 7 dapat terlihat bahwa peserta dalam penyuluhan dan pelatihan pengolahan hasil pertanian bukan hanya ibu-ibu namun juga remaja masyarakat Dusun Pulo.

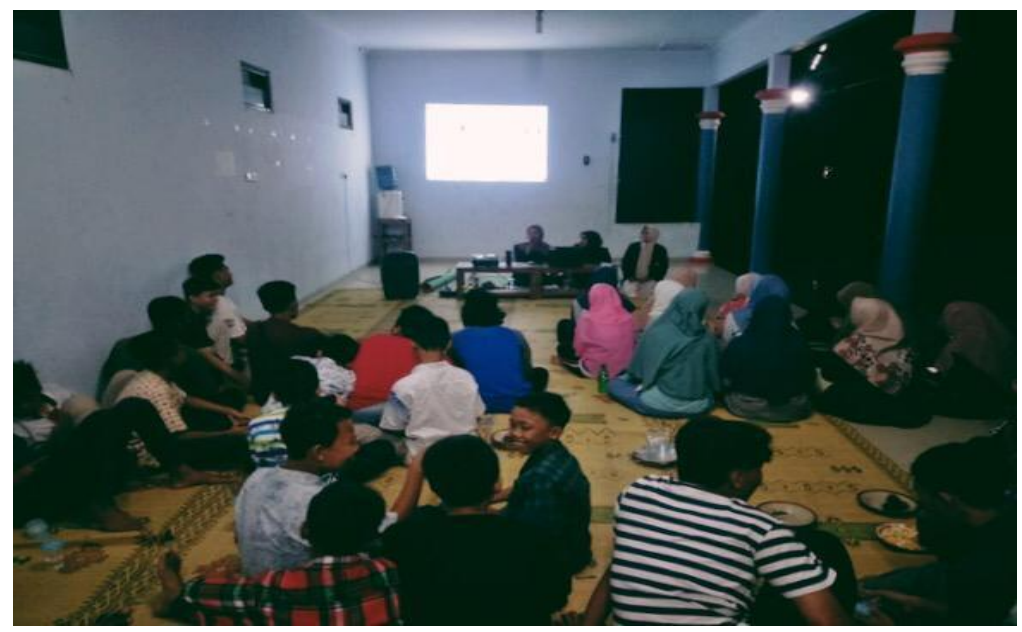

Gambar 7. Peserta Pelatihan TIK

Pelatihan dan pendampingan manajemen promosi berbasis TIK dilakukan dengan memanfaatkan media sosial berupa facebook dan instagram. Penggunaan media sosial instagram dapat digunakan sebagai media untuk mengirim foto dalam waktu cepat dapat dilihat oleh ratusan bahkan ribuan orang. Pemateri tidak hanya memberikan pelatihan penggunaan media sosial untuk media promosi produk namun juga melakukan pembuatan media sosial yang siap untuk digunakan anggota KWT Dusun Pulo untuk menunjang pemasaran produk.

\section{Kesimpulan}

Dusun Pulo Gulurejo mempunyai potensi hasil pertanian khusunya pisang yang sangat melimpah dimana KWT (Kelompok Wanita Tani) adalah sebagai kelompok pertanian yang mengelola usaha pertanian masyarakat diantaranya pisang jenis raja bandung/raja uter. Seiring berjalannya waktu KWT Dusun Pulo mendapatkan berbagai masalah diantaranya adalah melimpahnya hasil panen, hal ini mengakibatkan hasil pertanian tersebut hanya dijadikan makanan ternak. Dari Permasalahan tersebut pelaksanaan PKM di Dusun Pulo yaitu dengan mengadakan penyuluhan, pelatihan dan pendampingan pengolahan Sumber Daya Alam (SDA) lokal berupa pisang menjadi olahan yang bernilai ekonomis tinggi disertai dengan manajemen pemasaran produk dengan pemanfaatan TIK. Dari hasil program ini pisang yang sebelumnya 
mempunyai nilai ekonomis rendah dapat menjadi produk bernilai ekonomis tinggi yaitu berupa keripik pisang. Selain bernilai ekonomis tinggi pisang yang telah diolah menjadi lebih awet dan tahan lama.

\section{Daftar Pustaka}

[1] Cahyono, M. S., Harahap, D. H., \& Sukrajap, M. A. (2019). Penerapan Teknologi Produksi Makanan Olahan untuk Pengembangan Usaha Kecil dan Menengah di Kota Bandung. KACANEGARA Jurnal Pengabdian Pada Masyarakat, 3(1). doi:10.28989/kacanegara.v3i1.567

[2] Tambunan, T. T. H. (2011). Development of Micro, Small and Medium Enterprises and Their Constraints: A Story from Indonesia. Gadjah Mada International Journal of Business, 13(1), 21. doi:10.22146/gamaijb.5492

[3] Peter, T., \& Cathy, I. M. (2015). Networking for SMES in Uganda: A conceptual paper. African Journal of Business Management, 9(2), 43-49. doi:10.5897/ajbm2014.7534

[4] D. J. Storey(1994).Understanding the Small Business Sector. Thomson Learning

[5] Hassan, H., Tretiakov, A., Whiddett, D., \& Adon, I. (2014). Extent of E-procurement Use in SMEs: A Descriptive Study. Procedia - Social and Behavioral Sciences, 164, 264-270. doi:10.1016/j.sbspro.2014.11.076

[6] Nurdin, R. (2019). Peningkatan Kapasitas Produksi Usaha Wedang Uwuh Wonokromo Pleret Bantul Yogyakarta. KACANEGARA Jurnal Pengabdian Pada Masyarakat, 2(1), 7. doi:10.28989/kacanegara.v2i1.354

[7] Musa, H., \& Chinniah, M. (2016). Malaysian SMEs Development: Future and Challenges on Going Green. Procedia - Social and Behavioral Sciences, 224, 254-262. doi:10.1016/j.sbspro.2016.05.457

[8] Weerasiri, S. (2012). Attitudes and Awareness towards Environmental Management and its Impact on Environmental Management Practices (EMPs) of SMEs in Sri Lanka. Journal of Social and Development Sciences, 3(1), 16-23. doi:10.22610/jsds.v3i1.681

[9] Wengel, J. ter, \& Rodriguez, E. (2006). SME Export Performance in Indonesia After the Crisis. Small Business Economics, 26(1), 25-37. doi:10.1007/s11187-004-6491-y

[10] Altenburg, T., \& Meyer-Stamer, J. (1999). How to Promote Clusters: Policy Experiences from Latin America. World Development, 27(9), 1693-1713. doi:10.1016/s0305750x(99)00081-9

[11] Koçiu, L., Çelo, R., \& Mano, R. (2015). The Role Of Risk Culture In SMEs WHO Operate In The Gjirokastra Region. European Scientific Journal, 11(34).

[12] Kenny, B., \& Fahy, J. (2011). Smes' networking capability and international performance. Advances in Business Marketing and Purchasing, 17, 199-376.

[13] R. Trequattrini, giuseppe russo, and R. Lombardi. (2012).Defining Business Network. Int. J. Bus. Res. Manag., vol. 3, pp. 29-34.

[14] Hakimpoor, H., Tat, H. H., Khani, N., \& Samani, M. B. (2011). „Marketing Networking Dimensions (Mnds) and SMEs Performance, A New Conceptual Model,'. Australian Journal of Basic and Applied Sciences, 5(10), 1528-1533.

[15] Sudaryanto, ., Sajati, H., Kusumaningrum, A., Nugraheny, D., Aryanto, S., \& Wintolo, H. (2019). Pendampingan Pemasaran Produk Menggunakan Instagram Bagi Pelaku Usaha Mikro Kecil Menengah (UMKM) Di Kecamatan Pathuk Gunung Kidul. KACANEGARA Jurnal Pengabdian Pada Masyarakat, 3(1). doi:10.28989/kacanegara.v3i1.524 
Setia Wardani, Rianto, Anis Febri Nilansari

[16] Miller, K. C. (2012). Plasma Potassium Concentration and Content Changes After Banana Ingestion in Exercised Men. Journal of Athletic Training, 47(6), 648-654. doi: $10.4085 / 1062-6050-47.6 .05$ 